\title{
Current Knowledge of Tb Patients on Initiation of Treatment in Mettu Town
}

\author{
Dame Tesfaye $^{1}$ and Sileshi Dubale ${ }^{2 *}$ \\ ${ }^{1}$ Department of Nursing, Faculty of Health Sciences, Mettu University, Ethiopia \\ ${ }^{2}$ Department of Pharmacy, Faculty of Health Sciences, Mettu University, Ethiopia
}

Received: 阱 September 01, 2018; Published: 制 September 07, 2018

*Corresponding author: Sileshi Dubale, Department of Pharmacy, Faculty of Health Sciences, Mettu University, Mettu Ethiopia

\begin{abstract}
Background: Knowledge on causes \& initiation time of TB treatment of the community is critical and improve or worsen the transmission of the disease and treatment outcomes. Lack of awareness about the disease contribute to how compliance to chemotherapy and preventive measures of the disease. The objectives of this study were: To assess timeline of initiation of the treatment and current knowledge of patients in Mettu Town. A facility based descriptive cross-sectional study was conducted from April 28/2016 -May, 29/2016 and all patients attending Mettu Karl hospital and Mettu health center were included. Data was compiled and analyzed by using Statistical package for Social Sciences software (SPSS) version 20.0. Statistical significance was defined at a level of 0.05 and data was described with a confidence interval of $95 \%$.
\end{abstract}

Results: Forty-six (52.87\%) of respondents were female and $48.5 \%$ of the patients belong to age group of $15-29$. Fifty-four (62.07\%) of respondents residing in Urban setting and $54.02 \%$ were Oromo and $43.68 \%$ of respondents can read and write. Thirty-three (37.93\%) of respondents recognized the symptoms one month before they presented to health facility for the first time.

Conclusion and Recommendation: Significant numbers of the respondents were not knowledgeable and delayed in the initiation of the treatment. Appropriate intervention should be taken to reverse this problem.

Keywords: Treatment Initiation; Current Knowledge; Tuberculosis

\section{Background}

TB is a common and deadly infectious disease caused usually by mycobacterium tuberculosis in human. About $10 \%$ of latent infection eventually progress to active TB disease which, if left untreated kills about half of those infected. Once person develop active tuberculosis diseases, the symptoms of this disease may be mild for months and this leads to delays in seeking care and results in the transmission of bacteria from infected person to the others. Lack of understanding about tuberculosis, stigma toward the disease, inaccessibility of treatment is the main reason for delayed presentation; while lack of information and dissatisfaction of the treatment are the main reason of non-completion of the treatment. Perceived knowledge on the causes of tuberculosis and health seeking behavior among community members may reduce or increase the disease transmission. The spread of the disease increases due to failure to recognize the symptoms early, hence theses may delay the diagnosis of tuberculosis and treatment [15]. TB is re-emerging as a public health concern because of the low practices of peoples to prevent the transmission of $\mathrm{TB}$, inadequate health coverage, impact of HIV epidemic and negative attitude of patients on its transmission and treatment. Countries with high particularly sub Saharan Africa have witnessed profound increase in the number of tuberculosis cases [8-11].

In Ethiopia TB is major public health problem with increase rate of TB cases of $2.6 \%$ each year. Among these $97.1 \%$ are new cases of all forms TB. Smear positive cases account $32 \%$ and smear negative and extra pulmonary TB are 34\% and 32\% respectively. Lack of adequate knowledge about TB and non-compliance to treatment result in treatment failure. The likelihood of successful treatment of tuberculosis depends on the extent to which patient complete the pressured treatment regimen (adherence and noncompliance [12-14]. Better understanding of level of the knowledge and time of initiation of the treatment with regard to TB patient help for care provider and administrate to identity the gap and to take relevant action. Therefore, the purpose of this study was to assess timely initiation of the treatment and their current knowledge toward TB for patient on treatment in Mettu Town. 


\section{Objectives}

\section{General Objectives:}

To assess the initiation time of the treatment and current knowledge of patients in Mettu town.

\section{Specific Objective}

a) To assess the time line of initiation of the treatment of tuberculosis patient

b) To determine current knowledge of tuberculosis patient

c) To explore factors affecting time of initiation of $\mathrm{TB}$ treatment

\section{Method and Participants}

\section{Study Area}

The study was conducted in health facilities of Mettu town, from April 2016 to May, 2016. Mettu town is found in south west Ethiopia, in Ilu Aba Bor zone $600 \mathrm{~km}$ away from Addis Ababa, the capital of the country.

\section{Sample Size Determination}

All TB patient attending Mettu Karl Hospital and Mettu health center during the study period was included as convenient sample size.

Data Collection Procedure: Standard self-administered questionnaire and interview was developed in English and then changed to Afaan Oromo (Oromo Language) and then to English language). Questionnaires were further modified from guidelines and previous study before actual data collection. Data collection was face to face interview by principal investigator as it gets direct information from respondents.

Table 1: Time lines of treatment initiation of respondents in Mettu town, 2016.

\begin{tabular}{|c|c|c|c|}
\hline Variable & & Frequency & $\%$ \\
\hline \multirow[t]{5}{*}{ When recognized $1^{\text {st }}$ symptom } & 1 week back & 5 & 5.75 \\
\hline & 2 week back & 9 & 10.34 \\
\hline & 3 week back & 12 & 13.79 \\
\hline & 1 month back & 33 & 37.93 \\
\hline & $>1$ month & 28 & 32.18 \\
\hline \multirow[t]{4}{*}{ Frequency of health facility visit } & 1 times & 48 & 55.17 \\
\hline & 2 times & 29 & 33.33 \\
\hline & 3 times & 9 & 10.34 \\
\hline & 4 times & 1 & 1.15 \\
\hline \multirow[t]{4}{*}{ Delays for diagnosis } & $<1$ week & 37 & 42.53 \\
\hline & $1-2$ week & 35 & 40.23 \\
\hline & 2-4weeks & 10 & 11.49 \\
\hline & $>4$ weeks & 5 & 5.57 \\
\hline \multirow[t]{3}{*}{ Delays for treatment initiation } & Start immediately & 54 & 62.07 \\
\hline & $<1$ week & 28 & 32.18 \\
\hline & 1-2 week back & 5 & 5.75 \\
\hline \multirow[t]{2}{*}{ Treatment phase } & Intensive phase & 33 & 37.93 \\
\hline & Continuation phase & 54 & 62.07 \\
\hline
\end{tabular}

\section{Data Quality Assurance Measures}

The appropriately designed data collection instrument was used. Every day the collected data was reviewed and checked for completeness and consistently of the respondents. Pre- test was done on $5 \%$ of total population out of the study and necessary correction was made on the language clarity sequencing and workability of questionnaires.

\section{Data Analysis}

The collected data was analyzed manually after it was edited and checks for completeness and consistency, for further analysis, it was analyzed using SPSS. Descriptive analysis was used of describe the percentage of knowledge of TB patient and treatment initiation of TB patient to the area. Frequency distribution was using for qualitative data.

\section{Ethical Consideration}

Ethical clearance was obtained from ethical review board of Mattu university, college of public health and medical science department of nursing. Letter of permission present to Mattu Karl hospital and health center TB follow up clinic and verbal informed consent was obtained from each study is explain to respondent. Confidentiality of information was assured, and privacy of the respondent was maintained.

\section{Limitation of the study}

Since the patients on follow up attend health center by appointment some TB patients were not involved in the study during the study period. Shortage of time of data collection and lake of similar literature in the study area to compare and contrast the result. 


\section{Results}

\section{Time Lines of Treatment}

With regard to timelines of treatment initiation, the time when patients recognized the first symptoms, frequency of health facility visit before diagnosis, delays for diagnosis, and delays for treatment initiation and treatment phase were interviewed. Concerning of the time when they recognized first symptoms, thirty-three (37.93\%) of respondents recognized the symptoms one month before they presented to health facility for the first time. Fourth eight (55.17\%) of respondents visit health facility only once before diagnosis of TB, $37(42.53 \%)$ were diagnosed for TB within a week after the first visit and $62.07 \%$ were start treatment immediately after diagnosis of TB. Of total of respondents, $62.07 \%$ were in the continuation phase (Table 1).

Table 2: Knowledge of respondents about TB and its treatment in Mettu Town, 2016.

\begin{tabular}{|c|c|c|c|c|}
\hline Variables & & & Frequency & $\%$ \\
\hline \multirow[t]{8}{*}{ Signs \& symptoms } & Cough & & 83 & 95.4 \\
\hline & Night sweating & & 37 & 42.53 \\
\hline & Loss of appetite & & 20 & 23 \\
\hline & Bloody sputum & & 15 & 17.24 \\
\hline & Lymph node enlargement & & 17 & 19.54 \\
\hline & Fever & & 43 & 44.95 \\
\hline & Weight loss & & 28 & 32.18 \\
\hline & Easily fatigability & & 55 & 63.22 \\
\hline \multirow[t]{8}{*}{$\begin{array}{l}\text { Perceived knowledge on } \\
\text { Transmission of TB }\end{array}$} & & Coughing & 79 & 97.53 \\
\hline & & Sneezing & 44 & 54.32 \\
\hline & Yes (93.1\%) & Using the same utensil & 47 & 58.02 \\
\hline & & Sleeping together & 11 & 13.52 \\
\hline & & Drinking raw milk & 5 & 6.17 \\
\hline & & $\begin{array}{l}\text { Drinking contaminated } \\
\text { water }\end{array}$ & 2 & 2.47 \\
\hline & & Other & 2 & 2.47 \\
\hline & No & & 6 & 6.9 \\
\hline \multirow[t]{8}{*}{$\begin{array}{c}\text { Perceived knowledge on Anti-TB } \\
\text { treatment }\end{array}$} & If not interested & I can lead normal life & 1 & 1.15 \\
\hline & & $\begin{array}{l}\text { I will be cured by help } \\
\text { of God }\end{array}$ & 3 & 3.45 \\
\hline & & I may die & 74 & 85.06 \\
\hline & & $\begin{array}{l}\text { I can transmit the } \\
\text { disease }\end{array}$ & 11 & 12.64 \\
\hline & & I will be disabled & 1 & 1.15 \\
\hline & Total duration of the 4 months & & 2 & 2.3 \\
\hline & Treatment & 6 months & 80 & 91. \\
\hline & & 8 months & 5 & 5.75 \\
\hline \multirow[t]{4}{*}{$\begin{array}{l}\text { Perceived Knowledge on } \\
\text { Prevention }\end{array}$} & Yes $75(86.21 \%)$ & $\begin{array}{l}\text { Avoid coughing in front } \\
\text { of people }\end{array}$ & 73 & 97.33 \\
\hline & & $\begin{array}{l}\text { Not using the same } \\
\text { utensil }\end{array}$ & 37 & 47.93 \\
\hline & & Drinking boiled milk & 4 & 5.33 \\
\hline & No & & 12 & 13.79 \\
\hline \multirow[t]{3}{*}{$\begin{array}{c}\text { Importance of completion of the } \\
\text { Treatment }\end{array}$} & & To cure completely & 85 & 97.7 \\
\hline & & To avoid recurrence & 14 & 16.9 \\
\hline & & $\begin{array}{l}\text { To decrease } \\
\text { transmission }\end{array}$ & 5 & 5.75 \\
\hline
\end{tabular}




\section{Knowledge About Tb}

Concerning knowledge of respondent's questions about causes, signs and symptoms, transmission, curability, side effects of anti TB drugs, prevention and importance of completion of the treatment were asked. With regard to cause of TB 47 (54.02\%) of respondents were respond that TB caused by bacteria (Figure 1). Concerning perceived knowledge about sign and symptoms, transmission, curability, anti TB drugs treatment, prevention of TB was also asked and analyzed. Eighty-one $93.1 \%$ of respondents were respond as they know TB can transmitted and how it can be transmitted. Concerning anti TB drugs treatment $85.06 \%$ of respondents were know as they may die if they don't treat and 91.95\% of them know anti TB treatment was taken for 6 months. All of the respondents had been taking the drugs once per day. With regard to preventability of TB $86.21 \%$ know as TB is preventable disease. To sum up 13 knowledge-based question was asked and $82.76 \%$ were answered the question above mean (knowledgeable) and $17.24 \%$ were not knowledgeable (Table 2).

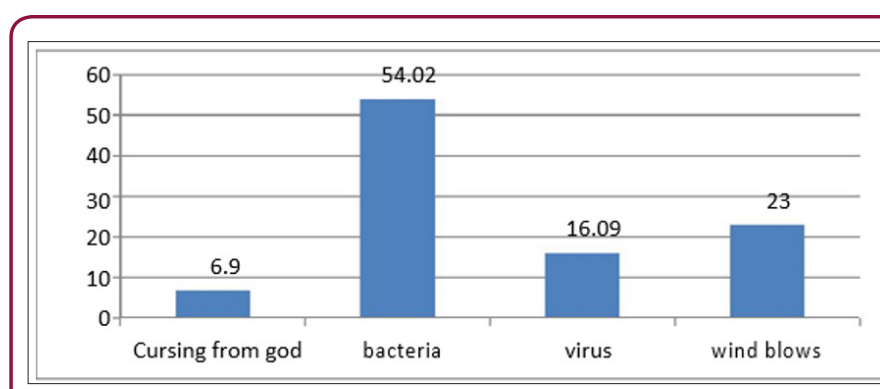

Figure 1: Knowledge about causes of TB of Mettu Karl hospital health center, 2016 .

The adjusted odd ratio (AOR) was calculated to identify associated factors and their significant. The analyzed risk factors are sex, age, patient residence, marital status, occupation and educational status of the Patients. Age of the patients, marital status and occupation had no such significant effect on knowledge and TB treatment dalliance. Sex, patient living, and educational status are significantly affecting patient TB treatment knowledge and they

take lion's share for dalliance of TB diagnosis and treatment. The odds of Females delayed from seeking TB treatment is 2.4(1.9-2.10) times than male in Mettu town with P-value of 0.003. Patients residing rural areas are delayed from seeking TB diagnosis and treatment $4.00(2.57-6.45)$ times than urban resident patients with p-value of 0.001. Illiterate patients were 10.76(5.019-13.09) times delayed from TB diagnosis and treatment than educated patient up to grade ten and above, with significant values (P-0.001) (Tables 2 \& 3).

Table 3: Factor Affecting Time of Initiation of TB Treatment in Mettu Town, 2016.

\begin{tabular}{|c|c|c|c|c|c|c|}
\hline Variables & & Frequency & $\%$ & AOR(95\%CI) & P-values & Intercept \\
\hline \multirow[t]{2}{*}{ Sex } & Male & 41 & 47.13 & 1 & & 0.029 \\
\hline & Female & 46 & 52.87 & $2.4(1.9-2.10)$ & 0.003 & \\
\hline \multirow[t]{3}{*}{ Age } & 15-29 Years & 42 & 48.5 & $0.329(0.215-0.049)$ & 0.806 & \\
\hline & 30-49 Years & 29 & 33.34 & 1 & & \\
\hline & $50+$ Years & 16 & 18.4 & $3.73(2.14-3.502)$ & 0.067 & 2.74 \\
\hline \multirow[t]{2}{*}{ Residence } & Urban & 54 & 62.07 & 1 & & 1.60 \\
\hline & Rural & 33 & 37.93 & $4.00(2.57-6.45)$ & 0.001 & \\
\hline \multirow[t]{4}{*}{ Marital Status } & Married & 55 & 63.22 & 1 & & 0.61 \\
\hline & Single & 21 & 24.14 & 2 & 0.78 & \\
\hline & Divorced & 6 & 6.9 & $0.97(009-0.23)$ & 0.56 & \\
\hline & Widowed & 5 & 5.75 & $2.30(1.9-4.56)$ & 0.047 & \\
\hline \multirow[t]{5}{*}{ Occupation } & Farmer & 36 & 41.38 & & 0.001 & \\
\hline & Merchant & 20 & 23 & & 0.67 & \\
\hline & $\begin{array}{l}\text { Government } \\
\text { Employed }\end{array}$ & 7 & 8.05 & 1 & & \\
\hline & Private Employed & 15 & 17.25 & & 0.08 & \\
\hline & student & 9 & 10.34 & & 0.46 & \\
\hline \multirow[t]{5}{*}{ Educational Status } & Illiterate & 31 & 35.63 & $10.76(5.019-13.09$ & 0.001 & 3.56 \\
\hline & Read and write & 18 & 20.7 & $4.06(2.34-6.04)$ & 0.023 & \\
\hline & Grade 1-8 & 15 & 17.24 & $1.62(0.87-2.03)$ & 0.09 & \\
\hline & Grade $9-10$ & 19 & 21.8 & $0.2(0.12-0.97)$ & 0.06 & \\
\hline & $10+$ & 4 & 4.6 & & & \\
\hline
\end{tabular}




\section{Discussion}

This study provided information regarding TB patients, timelines of treatment initiation, knowledge about tuberculosis and its treatment and factor affecting time of initiation of TB drug. In this study $88.5 \%$ of TB patients belong to economically productive age group (15-54years) which is slightly higher than the finding documented in WHO report which was $82 \%$ of cases. This difference might show that the finding of this study is recent and it was also done in specific area and my total population or respondents also not comparable with that study since WHO report is global study [16] and $54.02 \%$ of respondents responded that bacteria as the cause of tuberculosis whereas study done in south west Ethiopia in 2010 showed that $33.7 \%$ of $\mathrm{Tb}$ suspected patients had knowledge on the cause the disease. This study shows that $95.4 \%$ respondents mentioned that cough is one sign and symptom of TB which is slightly higher than the study done in Tanzania which is $72 \%$ of them know cough as one sign and symptom of TB [17]. Knowledge about route of the transmission of the disease is another important factor in TB prevention and control problem. In our study $93.1 \%$ of respondents responded as they know as TB can be transmitted, which is also slightly higher than study done in southwest Ethiopia which indicate $83.8 \%$ of patients have knowledge about route of transmission [18].

This difference is may be due to our study was conducted in the place where majority of study population were from urban area and they may had access of health information more. With regard to curability of the disease $97.7 \%$ of respondents were know that as TB is curable disease and $91.95 \%$ of them know anti TB treatment was taken for 6 months. This finding was the same with study conducted in Tanzania in which all respondents knew that TB was curable disease [19]. In this study $86.21 \%$ of respondents knew that as $\mathrm{Tb}$ is preventable disease with preventive method. This is slightly higher than study conducted in south west Ethiopia in which $82.3 \%$ of respondents know as $\mathrm{Tb}$ can be prevented and $69.9 \%$ know that not coughing / sneezing in front of other people as the main preventive measure [20]. Sex, Patient Residence and Educational status are significantly affecting Patient TB treatment knowledge and are significant factors for dalliance of TB diagnosis and treatment.

\section{Conclusion}

More than half of patient visited health facility only once before diagnosis. Majority of them started the treatment immediately after diagnosis and were in continuation phase. Most of them know as $\mathrm{Tb}$ can be transmitted and coughing in front of people and using the same utensil were common made of transmission known by respondents. Almost all respondents know as TB is curable disease and requires 6 months treatment more than half know that as anti TB treatment has no side effect. Majority of respondents know as TB is preventable disease and almost all of respondents respond avoidant direct coughing in front of people as the common preventive methods. Patients living rural areas and illiterate patients were delayed from seeking TB diagnosis and treatment. As early diagnosis and treatment initiation is important in TB control, attention should be given in all health facility. The focus of health education for general public should mainly on cause, route of transmission, side effects of anti TB treatment, sign and symptoms and preventive methods. In service training for health care provider on TB prevention and control should be strengthened to update their knowledge and skills. Further study should be done across the country on related topics. Focus should be given more for rural residence and un educated patients during health education

\section{Acknowledgement}

The investigators would like to acknowledge Mettu University for providing necessary resources.

\section{References}

1. WHO (2011) Tuberculosis fact sheet. p. 104.

2. Cassie Thomas (2009) A literature review of problem of delayed presentation for the treatment and noncompletion of treatment for tuberculosis in less developed countries and ways of addressing these problems using particular implementation of DOTs strategy and Journal of management in medicine. 16(4-5): 371-400.

3. Auer C (2000) Health seeking and perceived cause of tuberculosis among patients in manila. Journal of Tropical medicine and international health 5: 648-655.

4. Dye C (1999) Global burden of tuberculosis, estimated incidence, prevalence and mortality by country. Journal of American Medical Association 282(7): 677-686.

5. WHO (2013) Global tuberculosis control Geneva 08: 324-326.

6. World health organization (2011) global tuberculosis' control. Geneva, Switzerland.

7. Hang L Rider (2011) Epidemiology disease of Tb control in Paris and Berne by international union against TB and lung disease ( $\left(1^{\text {st }} e d n\right)$.

8. Espinal MA (2001) Global trends in resistance to anti tuberculosis drugs. New England Journal of Medicine (17): 1294-1303.

9. Michael KW, Belachew T, Jira C (2004) Tuberculosis defaulters from the dots regiemen in Jimma zone, south west Ethiopia. 42(4): 247-53.

10. WHO (2013) WHO global tuberculosis control Geneva, USA.

11. World health organization (2003) Treatment of tuberculosis; guide lines for national programmers. Geneva, Switzerland, world health organization.

12. (2000) Global tuberculosis control. WHO report. Geneva, World Helath Organization.

13. Booulue chimbartil (2008) Treatment seeking behaviors and improvement in adherence to treatment regiment of tuberculosis patients using intensive triad-model program.Thailand 39(3): 526-541.

14. Jane Mc, Harry JM Fnkenfliige, Valerie M, Anna P Nieboer (2010) TB treatment initiation and adherence in South African community influenced move by perception than by knowledge of tuberculosis. BMC public health 10: 72 .

15. Pe Mangeshol, E Sharo, WH Makunde (2007) community knowledge attitude and practice towards tuberculosis and its treatment in MP. central Tanzania health research Bulletin 9(1).

16. AM Kilalel (2009) Perception of tuberculosis and treatment seeking behavior in Ilala and Kinondon Municipalities in Tanzania. Journal of Health research 10(2): 89-94.

17. Mohammed A, yousif (2007) knowledge of tuberculosis. A survey among tuberculosis patients in Omdurman, Sudan, Sudanese. Journal of public health January 2(1): 711-713. 
18. Abebe G (2010) Knowledge, health seeking behavior and perceived stigma.

19. Mulenga C (2010) pulmonary TB patient's attitude to seek health.

\section{ISSN: 2574-1241}

DOI: 10.26717/BJSTR.2018.08.001709

Sileshi Dubale. Biomed J Sci \& Tech Res

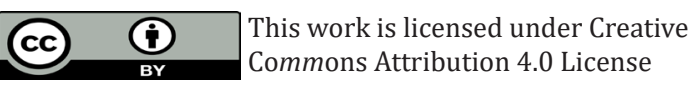

Submission Link: https://biomedres.us/submit-manuscript.php
20. (2005) Central statistical Agency, Ethiopia Demographic and health survey. Addis Ababa Ethiopia.

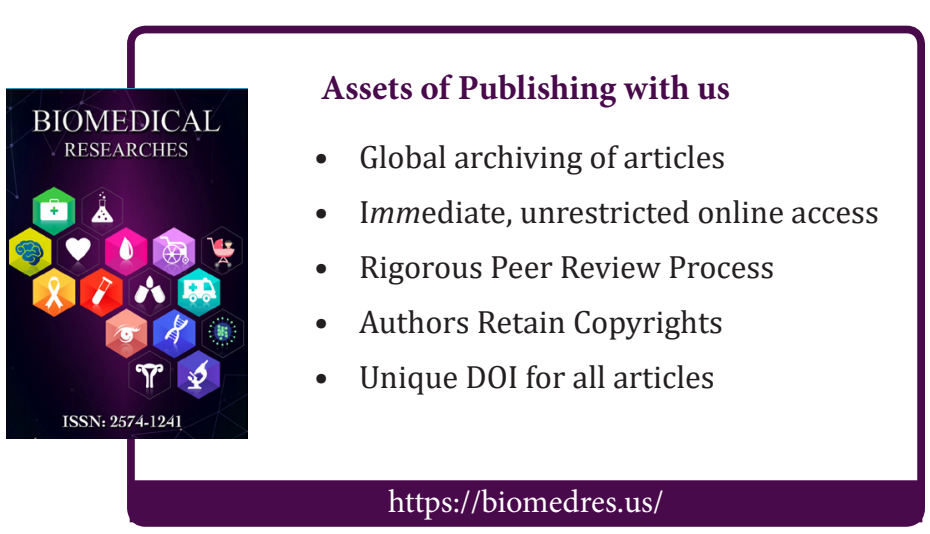

